\title{
Spectrophotometric Determination of Some Non-Sedating Antihistamines Using Erythrosine B
}

\author{
Michael E. El-Kommos, Samia M. El-Gizawy, Noha N. Atia, and Noha M. Hosny \\ Department of Pharmaceutical Analytical Chemistry, Faculty of Pharmacy, Assiut University, Assiut 71526, Egypt \\ Correspondence should be addressed to Noha M. Hosny; phar_nmh2011@yahoo.com
}

Received 9 April 2013; Accepted 12 May 2013

Academic Editors: A. Garcia Asuero, E. T. Haupt, B. K. Jena, J. B. MacMillan, and A. Senthil Kumar

Copyright ( 2013 Michael E. El-Kommos et al. This is an open access article distributed under the Creative Commons Attribution License, which permits unrestricted use, distribution, and reproduction in any medium, provided the original work is properly cited.

A simple and sensitive spectrophotometric method has been developed for the determination of cetirizine (I), ebastine (II), fexofenadine (III), ketotifen (IV), and loratadine (V) based on ion-pair complex formation with erythrosine B. The pink color of the produced complex was measured at $550 \mathrm{~nm}$ without solvent extraction. Appropriate conditions were established by studying the color reaction between erythrosine B and the studied drugs to obtain the maximum sensitivity. Beer-Lambert's law is obeyed in the concentration ranges $1-7,1-8$, and $1-6 \mu \mathrm{g} / \mathrm{mL}$ for (I, IV), (II, III), and (V), respectively. The method was validated according to ICH guidelines. The suggested method is applicable for the determination of the five investigated drugs in bulk and pharmaceutical dosage forms with excellent recoveries.

\section{Introduction}

In 1937, the first $\mathrm{H} 1$ antihistamine (thymo-ethyl-diethylamine) was synthesized. However, because of its weak activity and high toxicity, this compound was not used. Clinically useful $\mathrm{H} 1$ antihistamines such as phenbenzamine, pyrilamine, and diphenhydramine were introduced in the 1940s. Currently, H1 antihistamines constitute the second most commonly used class of medications after antibiotics. The older first-generation antihistamines are associated with troublesome sedative and antimuscarinic effects and are often termed "sedating antihistamines." The newer generations of antihistamines, which are essentially devoid of these effects, are correspondingly termed "non-sedating antihistamines."

Non-sedating antihistamines are of potential value in the management of allergic rhinitis in which they relieve nasal and conjunctival itching, sneezing, and rhinorrhoea. They are also useful in the treatment of acute and chronic urticaria [1].

Non-sedating antihistamines down regulate allergic inflammation directly through the H1-receptor by interfering with histamine action at H1-receptors on sensory neurons and small blood vessels. They also decrease the antigen presentation, expression of pro-inflammatory cytokines and cell adhesion molecules, and chemotaxis. In a concentrationdependent manner, they inhibit mast cell activation and histamine release [2].

Second-generation non-sedating antihistamines investigated are cetirizine (CTZ), ebastine (EBS), ketotifen (KET), and loratadine (LOR), while Fexofenadine (FXD) is one of the third-generation drugs. Their chemical structures are given in Figure 1 .

The studied drugs, CTZ, EBS, FXD, KET, and LOR are available in cheap generic forms, and they are considered over-the-counter (OTC) drugs and used without prescription with very low or no sedating effect.

Many procedures were described for quantitative determination of CTZ, EBS, FEX, KET, and LOR in the literature. Among these methods are liquid chromatography (HPLC) [3-8], gas chromatography (GC) [9-12], electrochemical [1317], spectrophotometric (derivative-spectrophotometry, formation of ion-pair complexes with methyl orange, bromocresol blue and eosin, and charge transfer with DDQ) [18-23], and fluorimetric methods [19, 22, 24-27].

In the present study, CTZ, EBS, FXD, KET, and LOR were determined through formation of ion-pair complex with erythrosine B (Figure 2), as acidic dye without extraction. 


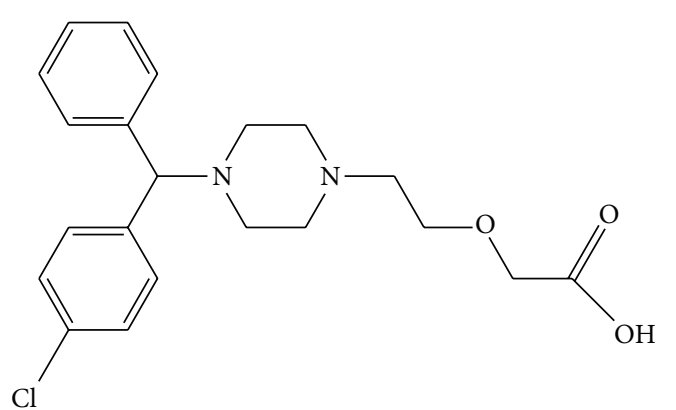

CTZ<smiles>CC(C)(C(=O)O)c1ccc(C(O)CCN2CCC(C(O)(c3ccccc3)c3ccccc3)CC2)cc1</smiles>

FXD<smiles>CC(C)(C)c1ccc(C(=O)CCCN2CCC(OC(c3ccccc3)c3ccccc3)CC2)cc1</smiles>

EBS<smiles>CN1CCC(=C2c3ccccc3CC(=O)c3sccc32)CC1</smiles>

KET<smiles>CCOC(=O)N1CCC(=C2c3ccc(Cl)cc3CCc3cccnc32)CC1</smiles>

LOR

FIGURE 1: Chemical structures of the investigated drugs.

Erythrosine B is the disodium salt of 2,4,5,7-tetraiodofluorescein, primarily used for food coloring and was used for spectrofluorimetric determination of imipramine [28].

The proposed method provides a rapid and sensitive procedure for the analysis of the studied drugs in pure and in pharmaceutical formulations. The proposed method provides an inexpensive tool for determination of the studied drugs in quality control laboratories especially in developing countries where the cost is the main concern.

\section{Experimental}

\subsection{Apparatus}

(i) Spectrophotometric measurements were carried out using a Shimadzu UV-1601 PC UV-Visible spectrophotometer (Tokyo, Japan) with $1 \mathrm{~cm}$ glass cells.

(ii) Jenway $3505 \mathrm{pH}$ meter (UK) was set to check $\mathrm{pH}$ values of acetate buffer solutions ( $\mathrm{pH} 3.3 ; 0.2 \mathrm{M})$.

\subsection{Materials and Reagents}

(i) CTZ $\mathrm{HCl}$ was kindly supplied by Egyptian International Pharmaceutical Industries Company E.I.P.I.Co. (10th of Ramadan city, Egypt).<smiles></smiles>

Figure 2: Chemical structure of erythrosine B.

(ii) EBS was kindly supplied by Global Napi Pharmaceutical Company (Giza, Egypt).

(iii) FXD $\mathrm{HCl}$ and LOR were kindly supplied by Amoun pharmaceutical company (Obour, Egypt).

(iv) KET fumarate was kindly supplied by Novartis pharmaceutical company (Cairo, Egypt).

(v) Erythrosine B (Market Harborough Leicestershire, $\mathrm{UK}), 0.15 \%$ solution in distilled water, was used.

(vi) Acetate buffer ( $\mathrm{pH} 3.3 ; 0.2 \mathrm{M}$ ) was prepared from acetic acid and sodium hydroxide [29].

(vii) All other chemicals and reagents used were of analytical grade. 
2.3. Pharmaceutical Formulations. All pharmaceutical formulations were obtained from the Egyptian market as follows:

(i) Epirizine tablets (labeled to contain $10 \mathrm{mg} \mathrm{CTZ} \mathrm{HCl}$ per tablet);

(ii) Evastine tablets (labeled to contain $10 \mathrm{mg}$ EBS per tablet);

(iii) Allerfen tablets (labeled to contain $60 \mathrm{mg}$ FXD HCl per tablet);

(iv) Zaditen tablets (labeled to contain $1 \mathrm{mg}$ KET fumarate per tablet);

(v) Mosedine tablets (labeled to contain $10 \mathrm{mg}$ LOR per tablet).

2.4. Preparation of Standard Solutions. Stock standard solutions were prepared to contain $1 \mathrm{mg} / \mathrm{mL}$ by dissolving $50.0 \mathrm{mg}$ of each drug in $25 \mathrm{~mL}$ methanol, and then the volumes were completed to $50 \mathrm{~mL}$ with the same solvent.

The working solutions were prepared by appropriate dilution of the stock solutions with methanol.

2.5. General Procedure. One milliliter of the working standard or sample solution of CTZ, EBS, FXD, KET, or LOR was transferred to $10 \mathrm{~mL}$ volumetric flask. Also, $0.45 \mathrm{~mL}$ of erythrosine $\mathrm{B}(0.15 \% \mathrm{w} / \mathrm{v})$ was added, then $1 \mathrm{~mL}$ of acetate buffer. The contents were left for 9 minutes at room temperature. Then, the mixture was diluted with distilled water, and the absorbance was measured at $550 \mathrm{~nm}$ for all drugs against a reagent blank prepared in the same manner.

2.6. Construction of Calibration Curves. Transfer different aliquots of standard solutions equivalent to $0.01-0.07,0.01-$ 0.08 , and $0.01-0.06 \mathrm{mg}$ of (I, IV), (II, III), and (V), respectively, to $10 \mathrm{~mL}$ volumetric flasks. Then, the assay was completed as under general procedure.

\section{Procedure for Tablets}

Accurately weighed powder samples obtained from 30 tablets, equivalent to $25 \mathrm{mg}$ of each drug, were suspended in methanol, and then the volumes were completed to the mark with the same solvent in $25 \mathrm{~mL}$ calibrated flasks, filtered and the first portion of the filtrate was rejected. Then, the assay was completed as under general procedure.

\section{Method Validation}

Typical analytical performance characteristics for the validation of procedures according to ICH Q2 guidelines were described in this study, including specificity, linearity, limit of detection, limit of quantification, precision, accuracy, recovery, and robustness [30].

4.1. Specificity. To assess the specificity of the method, the effect of diluents, excipients, and additives commonly used in pharmaceutical formulations such as lactose, titanium dioxide, starch, cellulose, and microcrystalline cellulose was studied.

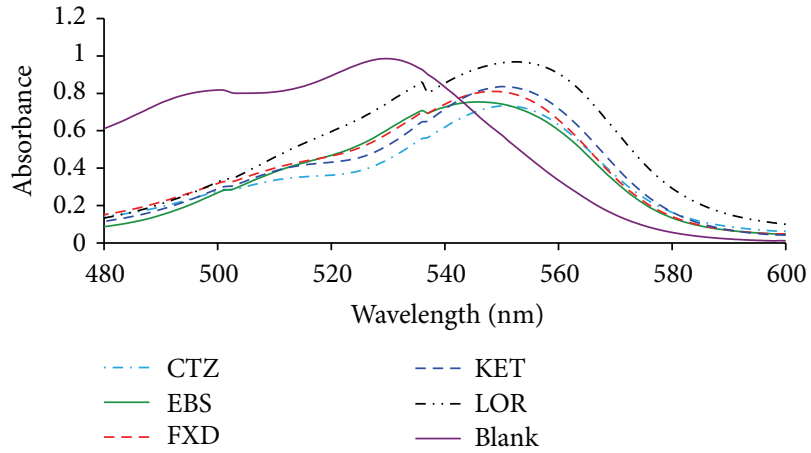

FIgURE 3: Absorption spectra of ion-pair complexes of CTZ, EBS, FXD, KET, and LOR $(6 \mu \mathrm{g} / \mathrm{mL})$ with erythrosine B.

4.2. Linearity. Linearity was determined either by plotting absorbance versus concentration or from linear regression equation $A=b C+a$, where $A$ is the absorbance of the ionpair complex solution, $b$ is the slope, $a$ is the intercept, and $C$ is the concentration of the drug.

4.3. Limits of Detection (LOD) and Quantification (LOQ). LOD and LOQ were calculated as $3.3 r / S$ and $10 r / S$, respectively, where $r$ is the standard deviation of $y$-intercept of the regression equation and $S$ is the slope of the calibration curve.

4.4. Accuracy. To determine the accuracy of the proposed method, three levels of drug concentrations (low, medium, and high) were prepared from stock solutions and analyzed $(n=6)$.

4.5. Precision. Intra-day precision of the proposed method was tested by replicate analysis of three separate solutions of the working standard of CTZ, EBS, FXD, KET, and LOR at three different concentration levels: low $(2 \mu \mathrm{g} / \mathrm{mL})$, middle $(4 \mu \mathrm{g} / \mathrm{mL})$, and high $(6 \mu \mathrm{g} / \mathrm{mL})$. This study was repeated for three days to determine the inter-day precision $(n=6)$.

4.6. Recovery. The recovery of the proposed method was determined using the standard addition technique, by adding a known amount of standard at three different levels to the pre-analyzed sample.

4.7. Robustness. The robustness of the proposed method was determined by studying the effect of minor changes on the absorbance of the formed complex: the $\mathrm{pH}$ of the media, buffer concentration, reaction time, and volume and concentration of the reagent on the method performance.

\section{Results and Discussion}

5.1. Absorption Spectra. The five studied drugs react with erythrosine $\mathrm{B}$ through an ion-pair salt formation, forming a pink chromophore with $\lambda_{\max }$ at $550 \mathrm{~nm}$ (Figure 3).

5.2. Optimum Reaction Conditions for Complex Formation. To optimize the assay parameters, the effects of $\mathrm{pH}$, reaction time, effect of temperature, erythrosine B concentration and 


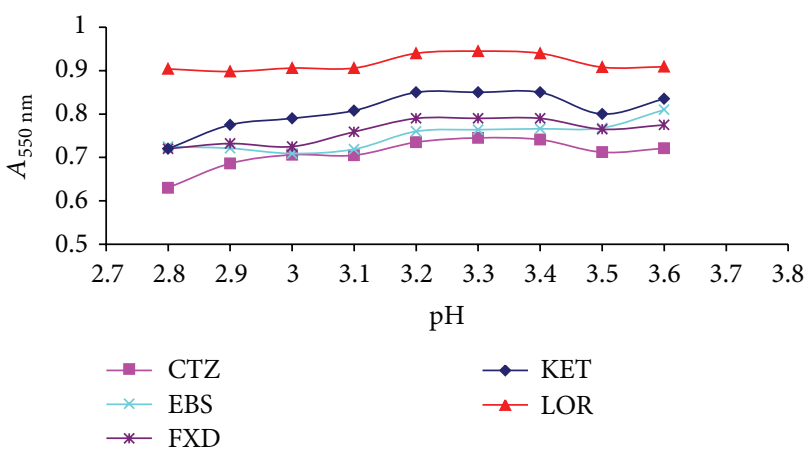

Figure 4: Effect of $\mathrm{pH}$ on the reaction of the studied drugs $(6 \mu \mathrm{g} / \mathrm{mL})$ with erythrosine B.



Figure 5: Effect of buffer concentration on the reaction of the studied drugs $(6 \mu \mathrm{g} / \mathrm{mL})$ with erythrosine B.

volume, order of addition of reactants, and the effect of solvent were studied.

5.2.1. Effect of $p H$. The procedure was carried out in the presence of various buffers such as phosphate, acetate, borate, and potassium hydrogen phthalate- $\mathrm{HCl}$ buffers. Acetate buffer was the best one giving the highest absorbance. Various concentrations of acetate buffer $(0.05-0.3 \mathrm{M})$ were also tried. It was found that the ion-pair formation was optimized using $0.2 \mathrm{M}$ for all drugs. At $\mathrm{pH} 3.7$ precipitation occurred; therefore acetate buffer in the $\mathrm{pH}$ range (2.8-3.6) was studied; the maximum color intensity was observed by using acetate buffer of $\mathrm{pH}$ 3.3, 0.2 M (Figures 4 and 5).

5.2.2. Effect of Reaction Time. The effect of time (Figure 6) and temperature on the developed reaction was judged based on the observation of complete color development which remained stable for one day. The optimum reaction time was studied from 0.0 to $14.0 \mathrm{~min}$. High temperature caused turbidity of the solution. It was observed that absorbance reached the maximum in $9 \mathrm{~min}$ at $25^{\circ} \mathrm{C}$ (room temperature).

5.2.3. Effect of Erythrosine B Concentration and Volume. Different volumes $(0.4-0.52 \mathrm{~mL})$ and various concentrations of erythrosine B $(0.05 \%-0.225 \% \mathrm{w} / \mathrm{v})$ were added to the studied drugs. Higher dye concentrations caused turbidity of the solution. It was found that the ion-pair formation was



FIgURE 6: Effect of reaction time on the ion-pair complexation of the studied drugs $(6 \mu \mathrm{g} / \mathrm{mL})$ with erythrosine B.

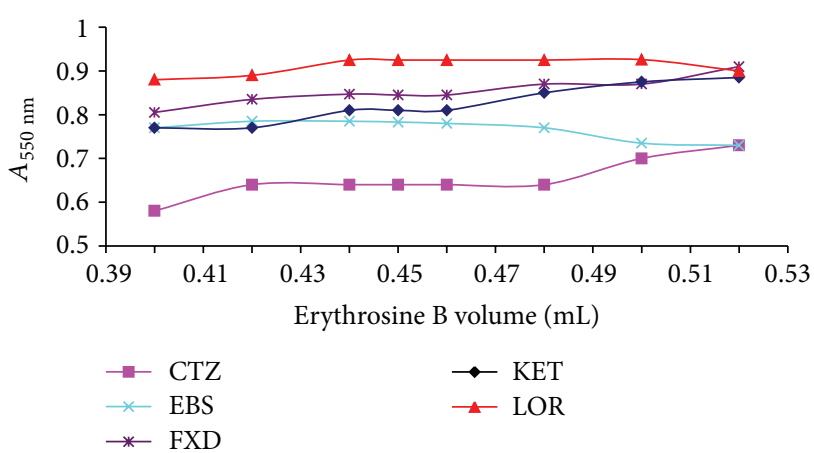

Figure 7: Effect of erythrosine B volume on the ion-pair complexation of the studied drugs $(6 \mu \mathrm{g} / \mathrm{mL})$ with erythrosine $\mathrm{B}$.

TABLE 1: The studied orders of addition of reactants.

\begin{tabular}{lcc}
\hline Order of addition & $\lambda_{\max }(\mathrm{nm})$ & Absorbance at $\lambda_{\max }$ \\
\hline Drug-buffer-dye & 546 & 0.647 \\
Drug-dye-buffer & $\mathbf{5 5 0}$ & $\mathbf{0 . 7 7 6}$ \\
Dye-drug-buffer & 544 & 0.637 \\
Dye-buffer-drug & 543 & 0.602 \\
\hline
\end{tabular}

EBS $(6 \mu \mathrm{g} / \mathrm{mL})$ was used as a representative example.

optimized using $0.45 \mathrm{~mL}$ of $0.15 \% \mathrm{w} / \mathrm{v}$ erythrosine B for all drugs (Figures 7 and 8).

5.2.4. Effect of Solvent. n-Butanol, ethanol, methanol, chloroform, dichloroethane, acetone, and distilled water were studied as diluting solvents. The maximum color intensity and highest absorbance values were observed with distilled water.

5.2.5. Effect of Order of Addition of Reactants. The studied orders of addition of reactants are summarized as shown in Table 1.

It was found that the most favorable sequence is drugdye-buffer for all the studied drugs to attain the highest color intensity and stability. 
TABLE 2: Spectral characteristics for the reaction of the studied drugs with erythrosine $\mathrm{B}^{\mathrm{a}}$.

\begin{tabular}{|c|c|c|c|c|c|}
\hline Parameter & CTZ & EBS & FXD & KET & LOR \\
\hline$\lambda_{\max }(\mathrm{nm})$ & 550 & 550 & 550 & 550 & 550 \\
\hline Linearity range $(\mu \mathrm{g} / \mathrm{mL})$ & $1-7$ & $1-8$ & $1-8$ & $1-7$ & $1-6$ \\
\hline$(r) \pm \mathrm{SD}^{*}$ & $0.9996 \pm 6.3 \times 10^{-4}$ & $0.9997 \pm 1.4 \times 10^{-4}$ & $0.9998 \pm 2.2 \times 10^{-4}$ & $0.9996 \pm 2.3 \times 10^{-4}$ & $0.9998 \pm 1.7 \times 10^{-4}$ \\
\hline$R^{2} \pm \mathrm{SD}^{*}$ & $0.9992 \pm 1.2 \times 10^{-3}$ & $0.9994 \pm 2.8 \times 10^{-4}$ & $0.9996 \pm 2.5 \times 10^{-5}$ & $0.9992 \pm 4.3 \times 10^{-4}$ & $0.9996 \pm 3.9 \times 10^{-4}$ \\
\hline Intercept $(a) \pm \mathrm{SD}^{*}$ & $-0.084 \pm 5.1 \times 10^{-3}$ & $-0.118 \pm 1.1 \times 10^{-2}$ & $-0.093 \pm 6.2 \times 10^{-3}$ & $-0.098 \pm 1.0 \times 10^{-3}$ & $-0.119 \pm 1.1 \times 10^{-2}$ \\
\hline Slope $(b) \pm \mathrm{SD}^{*}$ & $0.131 \pm 1.1 \times 10^{-3}$ & $0.143 \pm 3.7 \times 10^{-3}$ & $0.150 \pm 1.4 \times 10^{-3}$ & $0.157 \pm 1.7 \times 10^{-3}$ & $0.188 \pm 6.4 \times 10^{-3}$ \\
\hline $\mathrm{LOD}^{\mathrm{b}}(\mu \mathrm{g} / \mathrm{mL})$ & 0.13 & 0.25 & 0.14 & 0.21 & 0.19 \\
\hline $\operatorname{LOQ}^{c}(\mu \mathrm{g} / \mathrm{mL})$ & 0.39 & 0.77 & 0.41 & 0.64 & 0.58 \\
\hline
\end{tabular}

${ }^{\text {a }}$ Average of six replicates.

${ }^{\mathrm{b}}$ Limit of detection.

${ }^{\mathrm{c}}$ Limit of quantitation.

* Standard deviation.



FIGURE 8: Effect of erythrosine B concentration on ion-pair complexation of the studied drugs $(6 \mu \mathrm{g} / \mathrm{mL})$ with erythrosine B.

5.2.6. Stability Time. Absorbances of all formed complexes are stable for at least $2.5 \mathrm{~h}$ after final dilution for all the studied drugs.

5.2.7. Stoichiometric Ratio. Job's method of continuous variations [31] was employed using equimolar $\left(3 \times 10^{-4} \mathrm{M}\right)$ standard solutions of CTZ, FXD, KET, LOR, and $\left(2 \times 10^{-4} \mathrm{M}\right)$ of EBS with erythrosine $\mathrm{B}\left(3 \times 10^{-4}\right.$ and $2 \times 10^{-4} \mathrm{M}$, resp.). A series of solutions were prepared in which the total volume of drugs and erythrosine B was kept at $5 \mathrm{~mL}$ then diluted to volume in $10 \mathrm{~mL}$ calibrated flask with distilled water following the general procedure. The absorbance was measured at the optimum wavelength $(550 \mathrm{~nm})$.

The molar ratio of drug to dye in the ion-pair complex was found to be $1: 2$ (Figure 9).

\subsection{Validation of the Developed Method}

5.3.1. Linearity, Detection and Quantitation Limits. Under the described experimental conditions, standard calibration curves for CTZ, EBS, FXD, KET, and LOR with erythrosine B were constructed by plotting absorbance against concentration (Figure 10).

Conformity with Beer-Lambert's law was evident in the concentration range of the final solution cited in Table 2. The

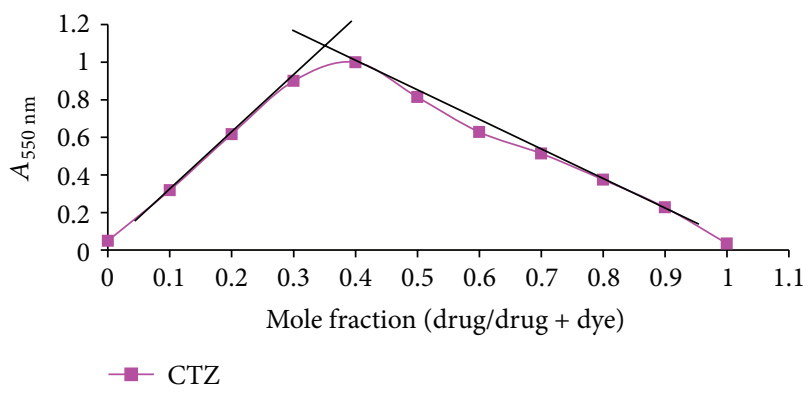

Figure 9: Continuous variation plot for CTZ as a representative example with erythrosine $\mathrm{B}$.



Figure 10: Calibration curves of the ion-pair complexes of the studied drugs with erythrosine $\mathrm{B}$.

linear regression equation, limit of detection, and limit of quantitation for each drug are presented also in Table 2. The correlation coefficients were $0.9996-0.9998$ indicating good linearity.

5.3.2. Precision and Accuracy. RSD\% values for CTZ, EBS, FXD, KET, and LOR for intra-day and inter-day precisions were ranged from 0.22 to 1.64 indicating good repeatability. Accuracy was determined by comparing measured 
TABLE 3: Accuracy and precision of the developed spectrophotometric method.

\begin{tabular}{|c|c|c|c|c|}
\hline \multirow{2}{*}{ Authentic drug } & \multirow{2}{*}{ Concentration $(\mu \mathrm{g} / \mathrm{mL})$} & \multicolumn{2}{|c|}{ RSD \% } & \multirow{2}{*}{ Accuracy ${ }^{*} \%$} \\
\hline & & Inter-day precision & Intra-day precision & \\
\hline \multirow{3}{*}{ CTZ } & 2 & 0.69 & 0.85 & 98.17 \\
\hline & 4 & 1.31 & 0.59 & 101.76 \\
\hline & 6 & 0.85 & 0.85 & 100.99 \\
\hline \multirow{3}{*}{ EBS } & 2 & 1.22 & 1.15 & 99.20 \\
\hline & 4 & 1.27 & 0.76 & 98.45 \\
\hline & 6 & 0.26 & 0.38 & 99.46 \\
\hline \multirow{3}{*}{ FXD } & 2 & 1.59 & 1.07 & 99.80 \\
\hline & 4 & 0.73 & 0.65 & 99.84 \\
\hline & 6 & 0.53 & 0.51 & 101.43 \\
\hline \multirow{3}{*}{ KET } & 2 & 0.98 & 0.59 & 99.33 \\
\hline & 4 & 0.73 & 0.71 & 100.24 \\
\hline & 6 & 0.37 & 0.28 & 101.90 \\
\hline \multirow{3}{*}{ LOR } & 2 & 1.64 & 1.29 & 99.87 \\
\hline & 4 & 0.62 & 0.45 & 99.66 \\
\hline & 6 & 0.33 & 0.22 & 99.83 \\
\hline
\end{tabular}

${ }^{*}$ Average of six replicates.

TABLE 4: Robustness of the developed spectrophotometric method.

\begin{tabular}{|c|c|c|c|c|c|}
\hline \multirow{2}{*}{ Drug } & \multicolumn{5}{|c|}{$\%$ Recovery $^{*} \pm$ SD } \\
\hline & CTZ & EBS & FXD & KET & LOR \\
\hline No variation $^{* *}$ & $101.1 \pm 0.76$ & $100.4 \pm 0.45$ & $100.2 \pm 0.93$ & $100.9 \pm 1.29$ & $100.2 \pm 1.20$ \\
\hline \multicolumn{6}{|l|}{$\mathrm{pH}$ of acetate buffer } \\
\hline 3.2 & $101.7 \pm 0.82$ & $100.7 \pm 1.16$ & $100.6 \pm 1.07$ & $100.9 \pm 0.61$ & $100.3 \pm 0.52$ \\
\hline 3.4 & $100.9 \pm 0.49$ & $100.9 \pm 0.27$ & $101.3 \pm 0.72$ & $102.3 \pm 1.22$ & $97.4 \pm 0.01$ \\
\hline \multicolumn{6}{|l|}{ Acetate buffer conc. } \\
\hline $0.15 \mathrm{M}$ & $100.8 \pm 0.57$ & $101.0 \pm 0.73$ & $100.2 \pm 0.63$ & $99.6 \pm 1.12$ & $99.4 \pm 0.84$ \\
\hline $0.25 \mathrm{M}$ & $101.7 \pm 0.08$ & $101.2 \pm 0.56$ & $101.4 \pm 0.02$ & $101.8 \pm 0.80$ & $98.7 \pm 0.91$ \\
\hline \multicolumn{6}{|l|}{ Erythrosine B conc. } \\
\hline $0.14 \% \mathrm{w} / \mathrm{v}$ & $100.1 \pm 1.14$ & $99.3 \pm 0.97$ & $100.2 \pm 1.11$ & $98.1 \pm 0.44$ & $99.4 \pm 0.67$ \\
\hline $0.16 \% \mathrm{w} / \mathrm{v}$ & $102.1 \pm 0.77$ & $98.2 \pm 0.63$ & $100.8 \pm 0.39$ & $100.7 \pm 0.36$ & $100.6 \pm 1.02$ \\
\hline \multicolumn{6}{|l|}{ Erythrosine B volume } \\
\hline $0.44 \mathrm{~mL}$ & $101.9 \pm 0.43$ & $98.5 \pm 0.89$ & $100.3 \pm 0.55$ & $98.6 \pm 0.32$ & $102.6 \pm 1.11$ \\
\hline $0.46 \mathrm{~mL}$ & $102.3 \pm 0.37$ & $102.3 \pm 1.57$ & $102.5 \pm 0.22$ & $103.0 \pm 0.54$ & $102.8 \pm 0.66$ \\
\hline \multicolumn{6}{|l|}{ Reaction time } \\
\hline $8 \mathrm{~min}$. & $101.6 \pm 0.15$ & $98.5 \pm 1.03$ & $100.9 \pm 0.83$ & $102.1 \pm 0.69$ & $99.1 \pm 1.11$ \\
\hline $10 \mathrm{~min}$. & $98.8 \pm 1.8$ & $102.9 \pm 0.42$ & $99.6 \pm 0.19$ & $98.9 \pm 1.29$ & $98.3 \pm 0.82$ \\
\hline
\end{tabular}

${ }^{*}$ Average of six replicates.

${ }^{* *}$ No variation in the assay condition of the proposed method.

concentrations of CTZ, EBS, FXD, KET, and LOR with the actual values and expressed as percentage in Table 3 . The accuracy of the developed method for the studied drugs ranged from $98.17 \%$ to $101.76 \%$ indicating acceptable accuracy. The obtained accuracy and precision were satisfactory for quality control measurements.

5.3.3. Robustness. The robustness of an analytical procedure refers to its capability to remain unaffected by small and deliberate variations in method parameters without changes in quantitation. For the determination of the method's robustness, five factors were selected from the analytical procedure to be examined in the robustness testing: $\mathrm{pH}$ and concentration of the buffer, volume and concentration of the dye, and reaction time. Results are shown in Table 4. It was found that none of these variables had a significant effect on the determination of investigated drugs. This provides an indication of the reliability of the proposed method during normal usage, so the developed spectrophotometric method is considered robust. 
TABLE 5: Assay of tablets of investigated non-sedating antihistamines by the developed method and reported methods.

\begin{tabular}{|c|c|c|c|c|c|}
\hline \multirow{2}{*}{ Authentic drug } & \multirow{2}{*}{ Dosage form } & \multicolumn{2}{|c|}{$\%$ Recovery $^{\mathrm{a}} \pm \mathrm{SD}$} & \multirow{2}{*}{$t$-value ${ }^{\mathrm{b}}$} & \multirow{2}{*}{$F$-value ${ }^{b}$} \\
\hline & & Proposed method & Reported method & & \\
\hline CTZ & Epirizine tablets & $99.97 \pm 0.65$ & $99.74 \pm 1.45^{*}$ & 0.36 & 4.94 \\
\hline EBS & Evastine tablets & $98.24 \pm 1.12$ & $98.07 \pm 1.49^{* *}$ & 0.22 & 1.77 \\
\hline FXD & Allerfen tablets & $99.39 \pm 0.90$ & $99.25 \pm 1.38^{*}$ & 0.22 & 2.36 \\
\hline KET & Zaditen tablets & $98.52 \pm 1.07$ & $98.18 \pm 1.07^{* * *}$ & 0.55 & 1.00 \\
\hline LOR & Mosedine tablets & $100.31 \pm 1.25$ & $99.20 \pm 0.97^{*}$ & 1.72 & 1.66 \\
\hline
\end{tabular}

${ }^{\text {a }}$ Average of six determinations \pm standard deviation.

${ }^{\mathrm{b}}$ Theoretical values at 95\% confidence limit; $t=2.228, F=5.053$.

* Reference [22].

** Reference [24].

**** Reference [21].

TABLE 6: Assay of tablets by standard addition method.

\begin{tabular}{|c|c|c|c|c|c|c|}
\hline Authentic drug & Dosage form & $\begin{array}{c}\text { Claimed taken } \\
(\mu \mathrm{g} / \mathrm{mL})\end{array}$ & $\begin{array}{l}\text { Authentic added } \\
(\mu \mathrm{g} / \mathrm{mL})\end{array}$ & $\begin{array}{l}\text { Found concentration } \\
(\mu \mathrm{g} / \mathrm{mL})\end{array}$ & $\%$ Recovery $\pm \mathrm{SD}^{*}$ & C.V \\
\hline \multirow{3}{*}{ CTZ } & \multirow{3}{*}{ Epirizine tablets } & \multirow{3}{*}{2} & 2 & 1.996 & $99.82 \pm 1.18$ & 1.18 \\
\hline & & & 3 & 2.995 & $99.83 \pm 1.09$ & 1.09 \\
\hline & & & 4 & 3.999 & $99.97 \pm 0.65$ & 0.65 \\
\hline \multirow{3}{*}{ EBS } & \multirow{3}{*}{ Evastine tablets } & \multirow{3}{*}{2} & 2 & 1.965 & $98.24 \pm 1.12$ & 1.14 \\
\hline & & & 3 & 2.996 & $99.87 \pm 1.53$ & 1.53 \\
\hline & & & 4 & 3.977 & $99.42 \pm 1.57$ & 1.58 \\
\hline \multirow{3}{*}{ FXD } & \multirow{3}{*}{ Allerfen tablets } & \multirow{3}{*}{2} & 2 & 2.005 & $100.23 \pm 1.31$ & 1.31 \\
\hline & & & 3 & 3.004 & $100.14 \pm 1.18$ & 1.18 \\
\hline & & & 4 & 3.976 & $99.39 \pm 0.90$ & 0.90 \\
\hline \multirow{3}{*}{ KET } & \multirow{3}{*}{ Zaditen tablets } & \multirow{3}{*}{2} & 2 & 1.967 & $98.36 \pm 1.41$ & 1.44 \\
\hline & & & 3 & 2.956 & $98.52 \pm 1.07$ & 1.09 \\
\hline & & & 4 & 3.988 & $99.69 \pm 1.44$ & 1.45 \\
\hline \multirow{3}{*}{ LOR } & \multirow{3}{*}{ Mosedine tablets } & \multirow{3}{*}{2} & 2 & 2.026 & $101.28 \pm 1.65$ & 1.63 \\
\hline & & & 3 & 3.009 & $100.31 \pm 1.25$ & 1.25 \\
\hline & & & 4 & 4.038 & $100.96 \pm 1.12$ & 1.11 \\
\hline
\end{tabular}

${ }^{*}$ Average of six replicates.

\section{Application of the Developed Method to Pharmaceutical Preparations}

Different commercial dosage forms of the studied drugs were successfully analyzed by the developed method, and results were compared with those obtained by reported methods $[21,22,24]$ as shown in Table 5. It was observed that there was no significant difference between results obtained by the developed method and the reported methods as indicated by $t$ - and $F$-tests. Additionally, recovery experiments were carried out for the studied drugs in their respective pharmaceutical formulations by standard addition method. The results in Table 6 indicate that the developed method is convenient for all investigated drugs with good recoveries, and there is no interference from either the coadministered drugs or frequently encountered excipients. The proposed method is sensitive, accurate, and precise. It is suitable for the determination of the studied drugs in their dosage forms and application in quality control laboratories.

\section{Conclusion}

A non-extractive spectrophotometric method was developed for the determination of some non-sedating antihistamines (cetirizine, ebastine, fexofenadine, ketotifen and loratadine) based on ion-pair complex formation with a simple and commercially available reagent (erythrosine B), which most ordinary analytical laboratories can afford. The method is sufficiently sensitive to permit determinations of as low as $1.0 \mu \mathrm{g} / \mathrm{mL}$. Unlike GC and HPLC procedures, the spectrophotometer is relatively simple to handle and affordable. The proposed method is simple, precise, accurate, and convenient. Hence, the proposed method should be useful for routine quality control purposes.

\section{Disclosure}

All the authors of the paper do not have a direct financial relation with the commercial identity mentioned in the paper. 


\section{Conflict of Interests}

All the authors declare that there is no conflict of interests in their submitted paper.

\section{References}

[1] S. C. M. Sweetman, The Complete Drug Reference, Pharmaceutical Press, London, UK, 36th edition, 2009.

[2] F. Simons, R. Estelle, and K. J. Simons, "Histamine and H1-antihistamines: celebrating a century of progress," Journal of Allergy and Clinical Immunology, vol. 128, no. 6, pp. 1139-1150, 2011.

[3] R. K. Trivedi, M. C. Patel, and S. B. Jadhav, "A rapid, stability indicating RP-UPLC method for simultaneous determination of ambroxol hydrochloride, cetirizine hydrochloride and antimicrobial preservatives in liquid pharmaceutical formulation," Scientia Pharmaceutica, vol. 79, no. 3, pp. 525-543, 2011.

[4] G. M. Hadad, S. Emara, and W. M. M. Mahmoud, "Development and validation of a stability-indicating RP-HPLC method for the determination of paracetamol with dantrolene or/and cetirizine and pseudoephedrine in two pharmaceutical dosage forms," Talanta, vol. 79, no. 5, pp. 1360-1367, 2009.

[5] L. Konieczna, A. Plenis, I. Olędzka, P. Kowalski, and T. Bączek, "Rapid RP-LC method with fluorescence detection for analysis of fexofenadine in human plasma," Chromatographia, vol. 71, no. 11-12, pp. 1081-1086, 2010.

[6] A. Plenis, L. Konieczn, I. Olędzka, and P. Kowalski, "Rapid analysis of loratadine in human serum by high-performance liquid chromatography with fluorescence detection," Acta Chromatographica, vol. 22, no. 1, pp. 69-79, 2010.

[7] F. Ibrahim, M. K. Sharaf El- Din, M. I. Eid, and M. E. K. Wahba, "Validated stability indicating liquid chromatographic determination of ebastine in pharmaceuticals after pre column derivatization: application to tablets and content uniformity testing," Chemistry Central Journal, vol. 5, no. 1, article 24, 2011.

[8] H. M. Maher, M. A. Sultan, and I. V. Olah, "Development of validated stability-indicating chromatographic method for the determination of fexofenadine hydrochloride and its related impurities in pharmaceutical tablets," Chemistry Central Journal, vol. 5, article 76, no. 1, 2011.

[9] C. Julien-Larose, M. Guerret, D. Lavene, and J. R. Kiechel, "Quantification of ketotifen and its metabolites in human plasma by gas chromatography mass spectrometry," Biomedical Mass Spectrometry, vol. 10, no. 3, pp. 136-142, 1983.

[10] H. Maurer and K. Pfleger, "Identification and differentiation of alkylamine antihistamines and their metabolites in urine by computerized gas chromatography-mass spectrometry," Journal of Chromatography, vol. 430, no. 1, pp. 31-41, 1988.

[11] R. Johnson, J. Christensen, and C. C. Lin, "Sensitive gas-liquid chromatographic method for the determination of loratadine and its major active metabolite, descarboethoxyloratadine, in human plasma using a nitrogen-phosphorus detector," Journal of Chromatography B, vol. 657, no. 1, pp. 125-131, 1994.

[12] H. J. Leis and E. Malle, "Deuterium-labelling and quantitative measurement of Ketotifen in human plasma by gas chromatography/negative ion chemical ionization mass spectrometry," Biological Mass Spectrometry, vol. 20, no. 8, pp. 467-470, 1991.

[13] R. H. Patil, R. N. Hegde, and S. T. Nandibewoor, "Electrooxidation and determination of antihistamine drug, cetirizine dihydrochloride at glassy carbon electrode modified with multiwalled carbon nanotubes," Colloids and Surfaces B, vol. 83, no. 1, pp. 133-138, 2011.
[14] M. Rachidi, K. Digua, P. Hubert, M. A. Faouzi, Y. Cherrah, and A. Bouklouze, "Analytical validation of potentiometric method for cetirizinium ion," Analytical Letters, vol. 39, no. 8, pp. 16991708, 2006.

[15] M. M. Aleksi, V. I. Radulovi, V. P. Kapetanovi, and V. M. Savi, "The possibility of simultaneous voltammetric determination of desloratadine and 3-Hydroxydesloratadine," Acta Chimica Slovenica, vol. 57, no. 3, pp. 686-692, 2010.

[16] M. M. Ghoneim, M. M. Mabrouk, A. M. Hassanein, and A. Tawfik, "Polarographic behaviour of loratadine and its direct determination in pharmaceutical formulation and human plasma by cathodic adsorptive stripping voltammetry," Journal of Pharmaceutical and Biomedical Analysis, vol. 25, no. 5-6, pp. 933-939, 2001.

[17] S. D. Güngör, "Electrooxidation of cetirizine dihydrochloride with a glassy carbon electrode," Pharmazie, vol. 59, no. 12, pp. 929-933, 2004.

[18] H. Mahgoub, A. A. Gazy, F. A. El-Yazbi, M. A. El-Sayed, and R. M. Youssef, "Spectrophotometric determination of binary mixtures of pseudoephedrine with some histamine H1-receptor antagonists using derivative ratio spectrum method," Journal of Pharmaceutical and Biomedical Analysis, vol. 31, no. 4, pp. 801809, 2003.

[19] M. K. Sharaf El-Din, F. A. Ibrahim, M. I. Eid, and M. E. K. Wahba, "First and second derivative synchronous fluorescence and spectrophotometric spectroscopy for the simultaneous determination of fexofenadine hydrochloride in presence of its degradation products. Application to stability studies," Acta Chimica Slovenica, vol. 58, no. 2, pp. 278-287, 2011.

[20] N. El-Kousy and L. I. Bebawy, "Determination of some antihistaminic drugs by atomic absorption spectrometry and colorimetric methods," Journal of Pharmaceutical and Biomedical Analysis, vol. 20, no. 4, pp. 671-679, 1999.

[21] C. S. P. Sastry and P. Y. Naidu, "Spectrophotometric estimation of Ketotifen fumarate in pharmaceutical formulations," Mikrochimica Acta, vol. 127, no. 3-4, pp. 219-223, 1997.

[22] A. A. Gazy, H. Mahgoub, F. A. El-Yazbi, M. A. El-Sayed, and R. M. Youssef, "Determination of some histamine H1-receptor antagonists in dosage forms," Journal of Pharmaceutical and Biomedical Analysis, vol. 30, no. 3, pp. 859-867, 2002.

[23] T. U. Sevgi, "Extractive spectrophotometric determination of cetirizine dihydrochloride in pure and pharmaceutical preparations," Journal of Food and Drug Analysis, vol. 18, no. 6, pp. 440-446, 2010.

[24] M. K. Sharaf El-Din, F. Ibrahim, M. I. Eid, and M. E. Wahba, "Validated spectroflurimetric determination of some H1 receptor antagonist drugs in pharmaceutical preparations through charge transfer complexation," Journal of Fluorescence, vol. 22, no. 1, pp. 175-191, 2012.

[25] M. I. Walash, F. Belal, N. El-Enany, M. Eid, and R. N. ElShaheny, "Stability-indicating micelle-enhanced spectrofluorimetric method for determination of loratadine and desloratadine in dosage forms," Luminescence, vol. 26, no. 6, pp. 670-679, 2011.

[26] Z. A. Alothman, N. Bukhari, S. Haider, S. M. Wabaidur, and A. A. Alwarthan, "Spectrofluorimetric determination of fexofenadine hydrochloride in pharmaceutical preparation using silver nanoparticles," Arabian Journal of Chemistry, vol. 3, no. 4, pp. 251-255, 2010.

[27] F. Ibrahim, M. K. El-Din, M. I. Eid, and M. E. Wahba, "Validated stability-indicating spectrofluorimetric methods for 
the determination of ebastine in pharmaceutical preparations," Chemistry Central Journal, vol. 5, article 11, 2011.

[28] P. R. Tomás, M. L. Carmen, T. Virginia, and S. Ciriaco, "Automatic extraction-spectrofluorimetric method for the determination of imipramine in pharmaceutical preparations," Analyst, vol. 120, no. 4, pp. 1103-1106, 1995.

[29] T. M. Wood, "Cellulolytic enzyme system of Trichoderma koningii. Separation of components attacking native cotton," Biochemical Journal, vol. 109, no. 2, pp. 217-227, 1968.

[30] Validation of Analytical Procedures, Methodology ICH Harmonized Tripartite Guideline, Having Reached Step 4 of the ICH Process at the ICH Steering Committee meeting, 1996.

[31] C. Y. Huang, "Determination of binding stoichiometry by the continuous variation method: the job plot," Methods in Enzymology, vol. 87, pp. 509-525, 1982. 

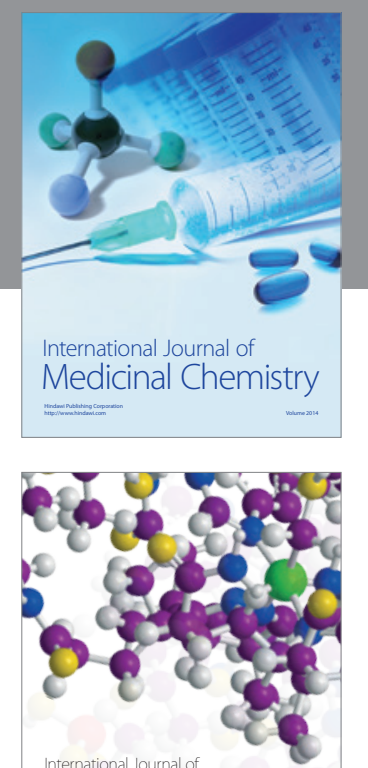

\section{Carbohydrate} Chemistry

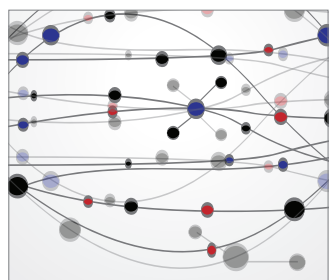

The Scientific World Journal
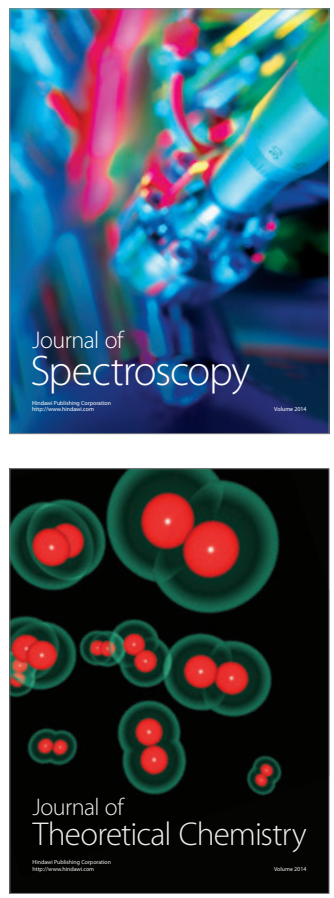
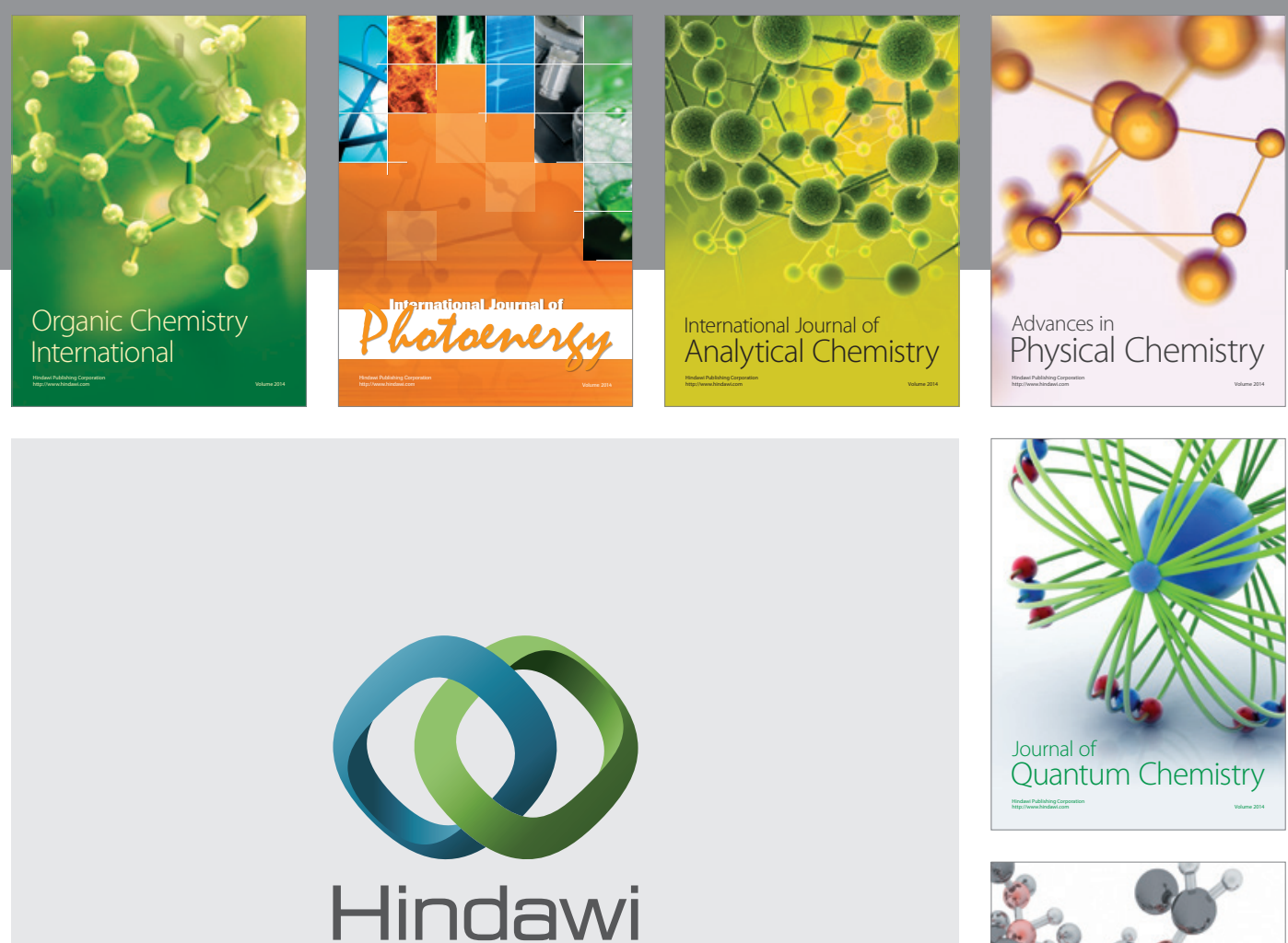

Submit your manuscripts at

http://www.hindawi.com



Analytical Methods

in Chemistry



Journal of

Applied Chemistry

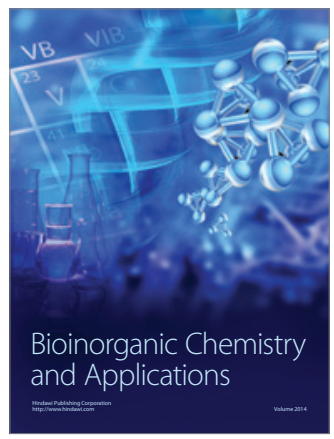

Inorganic Chemistry
